Alma Mater Studiorum - Università di Bologna DEPARTMENT OF ECONOMICS

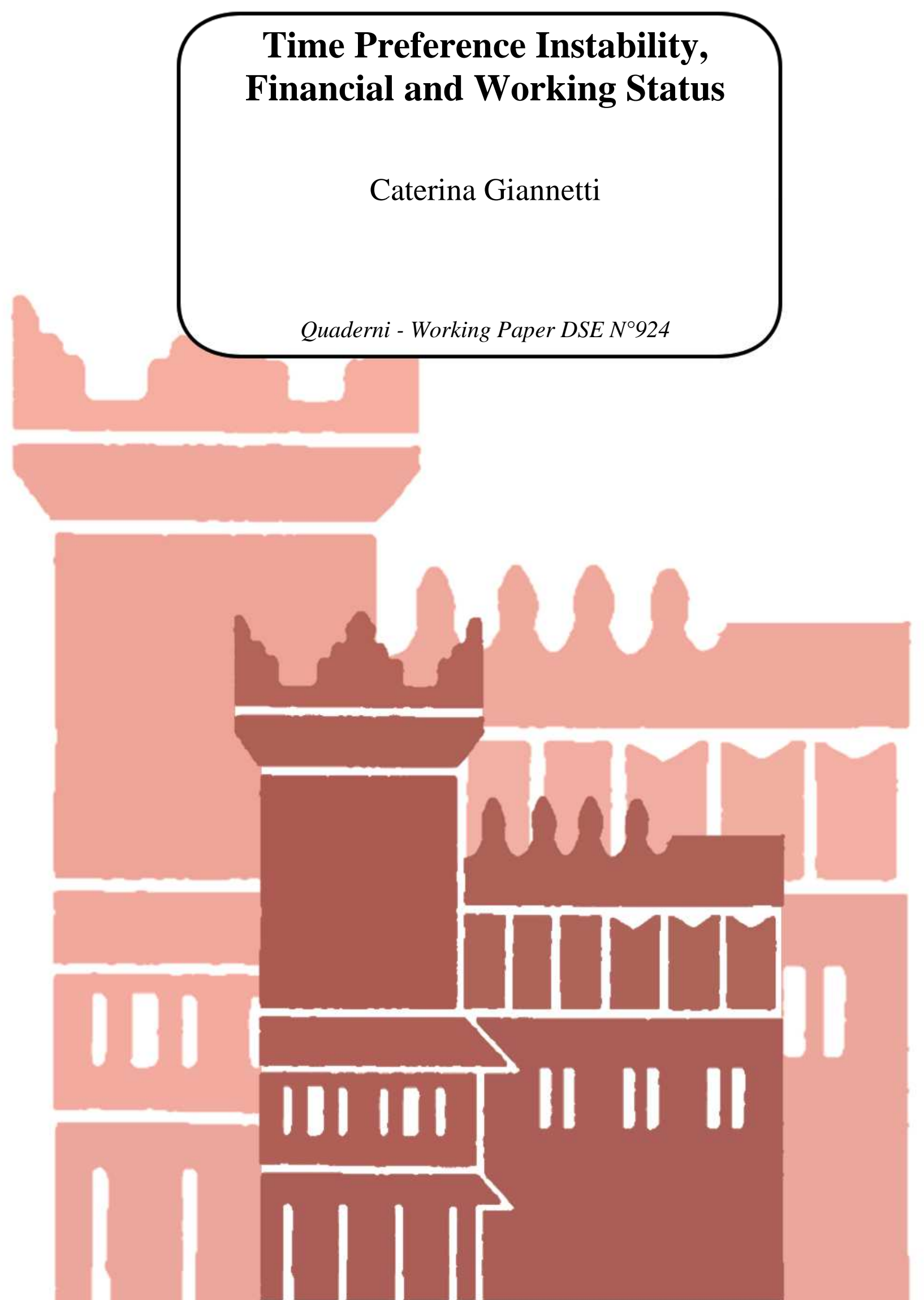




\title{
Time Preference Instability, Financial and Working Status
}

\author{
Caterina Giannetti ${ }^{1}$
}

12th February 2014

\begin{abstract}
In this paper we study the drivers of change in individuals' discount rates. Our panel dataset allows us to jointly consider socio-demographics, financial status and literacy, as well as job characteristics among the possible determinants. Our results suggest that individual time-preferences are not stable over time, especially among individuals who hold debts. Labour market variables do not play any direct role. A large part of the variation, however, is not explained by none these drivers. This supports the view that discount rates are related to an underlying unobservable individual trait.
\end{abstract}

Keywords: Time-preferences, financial constraints, debts

JEL Classification: C33, D1, D90

\footnotetext{
${ }^{1}$ University of Bologna. Department of Economics. Piazza Scaravilli, 2. 40126 Bologna. Italy. Email: caterina.giannetti@unibo.it
} 


\section{Introduction}

Most people - to a smaller or larger extent - are impatient, and tend to give less value to the distant future. There is robust evidence on this phenomena. However, measured discount rates rarely capture pure individual time preferences. Most often the elicited discounted rates are sensitive to other events which may affect individual life.

In particular, a recent strand of the literature has suggested that individual time-preferences might be linked to uncertainty of future prospects and market incompleteness. Recent empirical papers support this view. Some works have shown that discount rates systematically vary with household income and hours worked (Krupka and Stephens (2013)). Other works have additionally shown that opportunity to access credit market also substantially affect time preference factors: people who do not have access to means of redistributing income and consumption across time tend to discount utility more than individuals who are not constrained (Ventura (2003)). Finally, there is also research pointing out risk aversion as an important determinant of time preference parameters (Anderhub et al. (2001)). Empirically, however, it is difficult to pin down time-varying preferences and responses to changing economic incentives.

In this paper, we take advantage of the panel data from Italian Survey on Household Income and Wealth (SHIW) to investigate whether individual discount rates change across time, and if so, which are the drivers of the change. The main advantage of this dataset is to enable us to relate discount factors to a large number of social, economic, and demographic variables. In particular, in comparison to previous studies on this topic, we are able to simultaneously consider - in a panel setting - the effect of labour market outcomes and financial constraints. On the top of that, we are also able to control for individual level of financial literacy. Indeed, several scholars have highlighted the crucial role of financial literacy on household financial outcomes (e.g. Lusardi and Tufano (2009)). Finally, as it has been suggested in previous analyses, our study will also consider the level of (regional) market interest rates on mortgage, which potentially represent an important driver of individual rate of time preferences.

Our results suggest that the effects of socio-demographics are not significant. Similarly, no significant role seems to be exerted by the level of uncertainty the head of household is facing in the labour market, as well as by household position in the financial markets (e.g. credit access). However, head of households who hold debts are more likely to have unstable preferences. In addition, the effect of interest rates - though significant - is not economically sizeable.

Overall, these results are in line with the previous literature, which highlights that a significant part of individuals do not have stable preferences. Similarly, even in the current investigation, the residual effect (i.e. a large part of the variation in time-preferences) remains empirically unexplained by the explanatory variables. This opens the possibility that (unobservable) psychological factors might drive the residual change.

The structure of the paper is as follows: Section 2 briefly reviews the empirical literature, Section 3 presents in detail our dataset, whereas Section 4 discusses the econometric model. Section 5 discusses the results while Section 6 investigates the robustness of our results when 
data are split according to different socio-economics sub-groups. Section 7 summarizes and concludes our argument.

\section{Literature Review}

An increasing number of papers studying the determinant of time-preferences has recently appeared. For example, Ventura (2003) relies on one wave of the SHIW to study direct measures of time preferences. Based upon a set of questions different from ours, which were available in the year 2000, he develops for each head of households a utility discount factor and relates it to a large number of variables. In his cross-sectional analysis, he finds that individuals are impatient, with time preferences varying across age, education, income and wealth. Importantly, he also finds that risk aversion and financial constraints have a significant role in the determination of time preferences.

More recently, however, a growing interest has emerged on the dynamics of time preferences, and on the determinants of preferences instability. The current research aims to contribute along this line of research. The paper most closely to ours is Krupka and Stephens (2013), who rely on a two-years panel data from the U.S. (i.e. the SIME/DIME), to test whether measured discount rates change when factors that influence the respondent's nominal discount rates change. In particular, they find that discount rates fall when either household income or hours worked increase. Since both these changes are associated with the household's real interest rates in lending decisions, they interpret this evidence as supportive of the responsiveness of discount rates to factors affecting household's nominal interest rates. Compared to them we rely on a more comprehensive approach as we simultaneously consider in the same regressions the main factors which may affect household's discount rates. In particular, we both control -in a panel setting - for the (regional) rate of interests at which household's can borrow money for a mortgage and the head of household's income. In addition, we can control whether the heads of households have a permanent or a temporary job. This latter factor is an important contribution to the previous literature, which has suggested - but not yet investigated - that uncertainty may play an important role in the determination of discount rates.

Also related to the current research, even if it does not directly focus on temporal stability, it is the large field study conducted by Meier and Sprenger (2010a). They find that presentbiased individuals are more likely to borrow and, conditionally on this, they borrow more than dynamically consistent individuals. This relationship is robust when controlling for sociodemographics, credit constraints, and a proxy for interest rates. Meier and Sprenger (2010b) conduct another large field study, and show that the distribution of time preferences are quite stable over time. In particular, they find that individual fixed effects account for a large proportion of the variance in time preference measures, which are largely independent of sociodemographics and changes in income, unemployment and future liquidity (proxied from individual tax returns). The important role played in this analysis by individual fixed effects along with irrelevance of socio-demographics and other relevant economic factors - seems to 
suggest the existence of an underlying trait which drive time preferences. ${ }^{1}$ Consistent with the idea that discount rates are related to an underlying individual trait is also the work of Reuben et al. (2010), who report a positive and statistically significant relation between discount rates elicited with a monetary and a primary reward.

\section{Data Description}

Our empirical analysis relies on the Italian Survey on Household Income and Wealth (SHIW), a detailed dataset on household demographics, consumption, income, and wealth collected every two years by the Bank of Italy for a representative sample of the Italian population. We select our data from the 2008 and 2010 surveys, the years in which questions about individual discount rates and economically important indicators (such as the level of financial literacy) were introduced.

In each survey, the number of interviewed (heads of) households is more than 7000. The questionnaire used in the survey is always composed of a general part addressing aspects relevant to all households and a series of questions that are only administered to a random subset of the sample. Because we are particularly interested in the effect of labour market outcomes on individual time-preferences, we will only use data pertaining to the heads of households who were in the labor force in either one of the two surveys (i.e. employed, self-employed and unemployed), thus excluding retired persons, homemakers, and individuals leaving of independent means (about $60 \%$ of the sample). We will also restrict our attention to those individuals who participated in the study twice, that is we rely on a balanced sample. To avoid inconsistencies we remove from the sample few observations related to those household heads whose sex has changed across surveys and whose age varied more than the time-span between surveys. We are thus left with 1780 heads of household in each year. The choice to rely on this balanced sample is pertinent to our research for several reasons. First of all, we need at least two yearly observations, as we are mainly interested in studying any significant association between changes in the labour (and financial) market status and changes in time-preferences. Second the aggregate time preferences (see further below) appear stable in this balanced subsample. Finally, although with some differences, the main results across the two yearly (unbalanced) samples are quite similar.

Table (1) reports the description of the variables used in our empirical investigation while Table (2) reports descriptive statistics for our selected panel.

\subsection{Measuring discount factors.}

Discount rates were elicited by asking to the head of the family the following question:

\footnotetext{
${ }^{1}$ Although controlling for unobservable individual traits, the inclusion of individual fixed-effects does not help to "explain" the determinants of the change.
} 
"You have won the lottery and will receive a sum equal to your household's net yearly revenue. You will receive the money in a year's time. However, if you give up part of the sum you can collect the rest of your win immediately. To obtain the money immediately would you give up 10 per cent of your win?"

If the respondent's answer is "yes", the interviewer asks for a discount of 20 per cent, whereas if the answer is "no" the interviewer asks for a discount of 5 per cent. In this latter case, if the answer is again "no" the interviewer also asks whether the head of the family is willing to give up the money for a discount of 2 per cent.

In year 2008, this question was only administered to a random subset of household, while in year 2010 this question was part of the survey for all respondents. Furthermore, since the order of the questions may affect the response, in year 2010 for half of the sample the order of the first two questions was switched. We then use the midpoint of the range of two discount values to determine the implied discount rate. Thus, for example, if a respondent is willing to accept a reduction of 10 per cent but will not accept a discount of 20 per cent, the midpoint is 15 per cent.

Several techniques are available to elicit individual discount rates and there is no consensus on best practices (Hardisty et al. (2013)). ${ }^{2}$ Differences in studies may be thus attributed to differences in elicitation technique (Frederick (2003),Hardisty et al. (2013)). Eliciting individual discount rates as we do (i.e. through multiple staircase choice-method) has advantages with respect to previous methods because it avoids answer inconsistencies and appears easier for participants to understand (Hardisty et al. (2013)). Moreover, in our case there is no need to infer ex-post the discount rates (and thus imposing a functional form for preferences) as participants are directly asked the value of their discount rates (i.e. the percentage).

Before examining the individual variations of time preferences in our balanced sample, it is important to check whether the distributions of aggregate time-preferences is stable through time. Indeed, the aggregate empirical distributions appear very similar in year 2008 and in year 2010, for both the full (not reported) and the balanced sample (see Figure (1)). Nonparametric Wilcoxon rank sum tests also support the null hypothesis of equal distributions over the two years ( $p$-value $=0.2036$ ), although the evidence for the balanced sample is less strong ( $\mathrm{p}$-value $=0.0256$ ). Moreover, in the balanced sample, the correlation between the two yearly measures is 0.27 , a value very much in line with previous studies, which suggest the reliability of this indicator.

Finally, Figure (2) plots an histogram of the individual variation in discount rates between year 2008 and year 2010. This figure indicates that the distribution is generally symmetric, cen-

\footnotetext{
${ }^{2}$ Time preferences have been elicited with two methods: matching and choice-based methods. The matching method asks for the indifference point directly. For example it asks the participant what amount " $X$ " would make him indifferent between $\$ 10$ immediately and $\$ X$ in one year. The choice-based methods generally present participants with a series of binary comparisons to infer an indifference point. For example, it asks the participant to choose between receiving $\$ 10$ immediately or $\$ 11$ in one year, and subsequently between $\$ 10$ and $\$ 12$ in one year. If he chose in the first case the immediate option and in the second case the future option, the participant's indifference point would roughly be considered $\$ 11.50$ and he would be attributed (with an exponential method) a discount rate of $14 \%$. Within this latter method it is possible to further distinguish different elicitation techniques. The fixed-sequence titration, which presents participants with a pre-set list of choices, and the multiple-staircase, which dynamically select the choice option upon participants' previous answers. For a detailed description on advantages and drawbacks of these methods, see Hardisty et al. (2013).
} 
Figure 1: Discount rates in 2008 and 2010
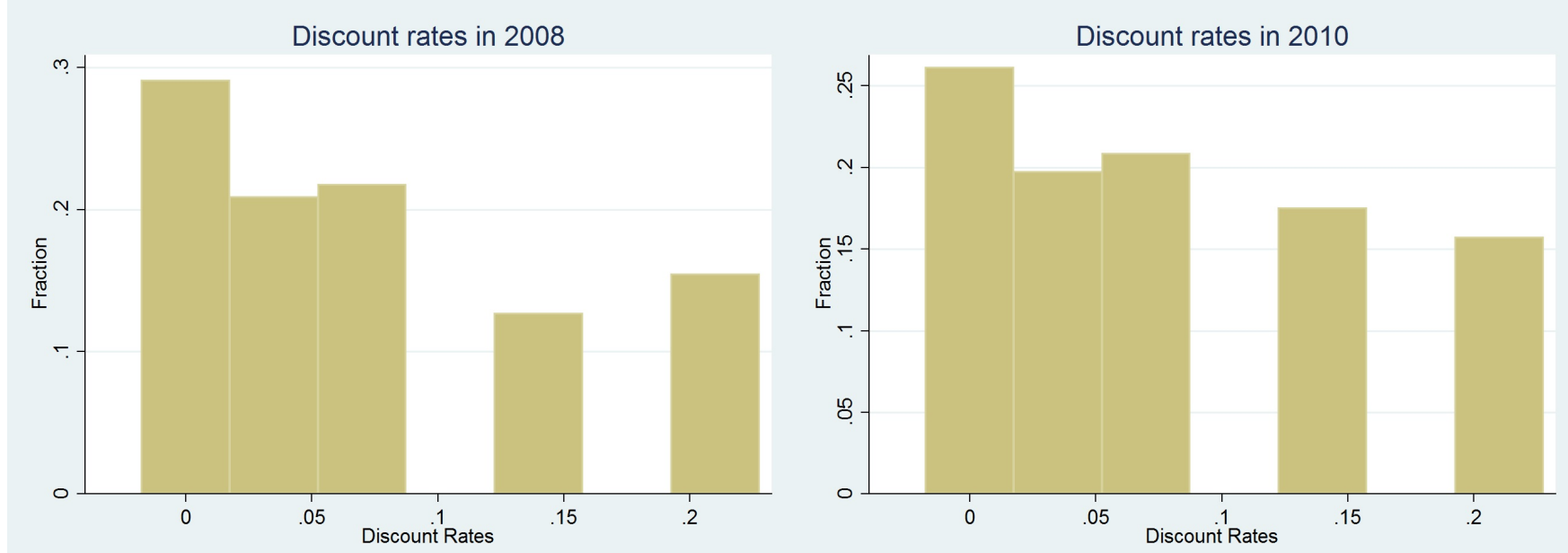

tered around zero, with a large mass at zero, but also with a considerable number of extreme observations of large changes. If individual time-preferences were stable, we should not observe such a remarkable numbers of observations larger than zero. The aim of our empirical investigation is to study the main drivers of such a change.

\subsection{Measuring financial status and literacy.}

The survey also provides a rich set of information on household financial status. In particular, it contains questions about households that were denied credit or discouraged from borrowing during the year. Differently from previous work, however, we can rely on direct measures of financial constraints. Specifically, we used the following questions to determine indicators of financial constraints:

- Did the household contact a bank or financial company in 200_with a view to obtaining a loan or mortgage? Yes I No

- Was the request granted in full, granted in part or refused? granted in full I granted in part I refused

- During 200_did you or a member of the household consider applying for a mortgage or a loan from a bank or financial company but later change your mind because you thought the request would be refused? Yes I No

In particular, we constructed an indicator "ASK CREDIT", which is a dummy variable equal to one if the respondent had contacted a bank or a financial company to obtain a loan or a mortgage, and - conditional on having looked for credit - two indicators of financial constraints: "FIN CONSTRAINTS 1", which is a dummy variable equal to one if the respondent had either been refused or partially granted a loan or mortgage, and zero otherwise; and "FIN CONSTRAINED 2", which is a dummy variable equal to one where "FIN CONSTRAINED 1" is equal 
Figure 2: CHANGE IN DISCOUNT RATES

This figure represents the histogram of the individual variation in discount rates between year 2008 and year 2010.

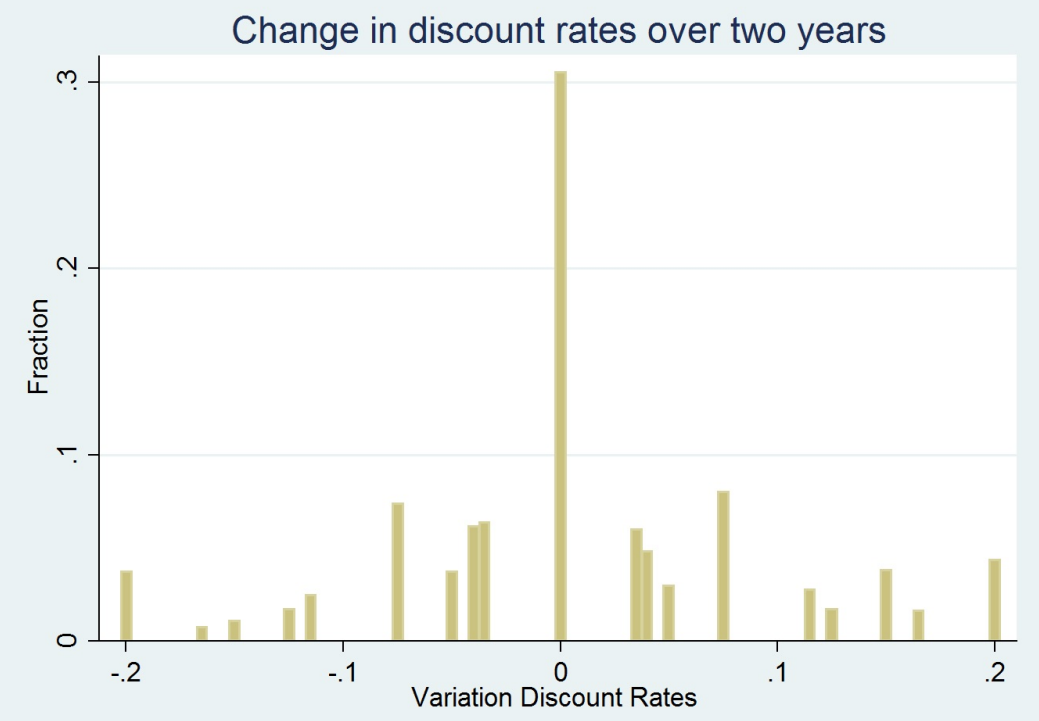

to one or the respondent had been discouraged to apply for a loan and mortgage, and zero otherwise. Furthermore, in order to take into account the possibility of having financial access, we constructed a dummy variable equal to one wherever the respondent had a bank or post-office (current or savings) account ("BANK ACCOUNT"). Less than $2 \%$ of Italian households reported being financially constrained. This percentage is slightly above $7 \%$ when one takes into account the households that were discouraged to apply for a loan. We can also observe that more than $90 \%$ of the respondents had access to either a bank or post-account.

We are also able to compute an indicator on the level of financial literacy of the head of household, as in the 2008 and 2010 surveys, the financial literacy module was part of the survey for all respondents. However, only three out of the six original questions in 2008 were directly comparable with those available in the survey in 2010. Therefore, to compare the level of financial literacy across across surveys, and to additionally have a concise indicator of financial literacy that is not affected by total numbers of questions, we construct the following min-max indicator:

$$
\text { MIN MAX LITERACY }=\frac{\text { \#CORRECT ANSWERS-MIN CORRECT ANSWERS }}{\text { MAXCORRECT ANSWERS-MIN CORRECT ANSWERS }}
$$

which basically relates the total number of correct answers given by the respondent (the numerator) with the maximum and minimum values of possible correct answers (the denominator). The main advantage of this indicator is to vary from 0 to 1 , while taking into account the different number of posed questions in each year.

\subsection{Interest rates}

After years of rapid expansion, credit to Italian households began to slow as response to the rise on interest rates that was substantial over all Italian regions and provinces (see Figure 
Figure 3: EVOLUTION OF REGIONAL INTEREST RATES ON MORTGAGE

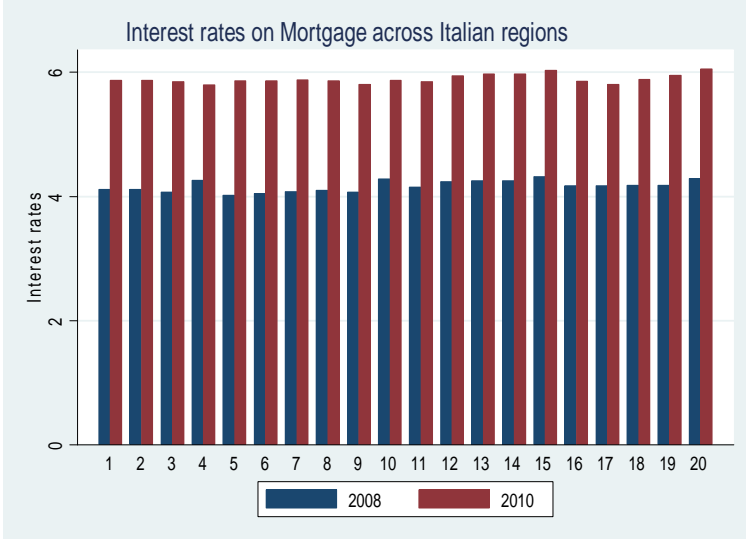

3). In particular, banks declared that they had increased the margins applied to average loans and not just to the riskier ones. As a consequence, the percentage of households with debts in 2010 survey (30.28\%) is smaller compared with that in 2008 (33.48\%). The drop in credit market participation is mainly accounted for low-income households and those headed by a self-employed person or by an insecure worker (see also Magri and Pico (2012)).

To have a clear picture of the financial condition of the households, we thus control for all type of household debts. We consequently include in our regressions the variable "DEBTS", which is a dummy equal to one where the respondent reported having either a mortgage or a debt for acquiring goods (e.g. vehicle), or a debts towards family or friends. In each year, we will also control for the level of interests at which households may obtain a mortgage in the province they are living in.

\subsection{Households' characteristics.}

As highlighted in previous research, it is essential to consider (and possibly to jointly measure) individual risk aversion and time preferences, as these two measures are strictly intertwined (e.g. Prelec and Loewenstein (1991), Anderhub et al. (2001)). In the survey, it is possible to use the following question to capture (financial) risk aversion on the part of the head of the households:

- How would you describe your attitude when you manage your financial investments? Are you someone who looks for very high returns, regardless of a high risk of losing part of your capital I a good return, with reasonable security for your invested capital | a reasonable return, with a good degree of security for your invested capital I low returns, without any risk of losing your capital

Specifically, we constructed a categorical variable ("FINANCIAL RISK AVERSION") which is equal to four for individuals who are highly risk averse (i.e. they prefer low return and low risk of losing their capital), to three for individuals who are moderately risk averse (i.e. they prefer reasonable return with a good degree of security), to two for individuals who are moderately 
risk loving (i.e. they prefer good return with reasonable security for their capital), and to one for individuals who are highly risk loving (i.e. they prefer high returns regardless of the risk of losing part of their capital).

We also collected demographic information, including the household head's sex ("SEX"), his or her level of education ("EDUCATION"), his or her civil status ("SINGLE", "DivORCED", "WIDOW" or "MARRIED"), and income ("LOG INCOME"). In particular, the variable "LOG INCOME" measures all possible sources of income for each respondent in each year, including any possible transfer from private or public entities. We can also include information on the household's property ("HOUSE PROPERTY"), size ("HOUSEHOLD SIZE"), and on the number of persons in the household who are income holders ("FAMILY INCOME HOLDERS").

\section{Model Specification}

The first model specification we test is a standard linear model that can be expressed as

Discount ratio $_{i t}=\alpha$ SOCIO-ECONOMICS CHARACTERISTICS $_{i t}+\beta$ JOB CHARACTERISTICS $_{i t}+\theta$ FINANCIAL SITUATION $_{i t}+\delta$ INTEREST RATES $_{i t}+\gamma 1($ year $=2010)+\mu_{i}+\varepsilon_{i t}$

where $i$ represents the head of the household and $t$ indexes year. In this specification we allow the unobserved individual effects $\mu_{i}$ to be correlated with the explanatory variables. If preferences are stable over time, the residual effect of time, $\gamma$, should not be significant.

Since discount rates are measured as a proportion - and necessarily bounded between zero and one, standard linear models may not provide an accurate description for the entire distribution of discount rates.

In this paper we rely on the work of Papke and Wooldridge (2008) to estimate a fractional response models for panel data with a large cross-sectional dimension and few time periods, allowing the constant unobserved effects to be correlated with the explanatory variables. To model the unobserved effects, Papke and Wooldridge (2008) employ the Mundlak's and Chamberlain's device and use a probit response function. Similarly, we use the two methods they proposed to estimate a fractional probit model. The first is the pooled Bernoulli quasi-MLF, where the leftover serial dependence is treated as a nuisance to be addressed through corrected standard errors. The second approach relies on the generalized estimating equation (GEE), which may possibly enhance efficiency in case of misspecification of the conditional variance matrix (see Papke and Wooldridge (2008)). In both cases, to make the fixed effects estimates directly comparable to the quasi-MLE estimates, we add the time averages of the explanatory variables to control for correlation between the $\mu_{i}$ and the explanatory variables.

\section{Results}

We first apply a standard regression model with fixed effects to estimate equation (1). As highlighted above, this model does not ensure that the expected value is between zero and one. The 
coefficients, however, are easier to interpret as the marginal effects correspond to the estimated coefficients. Table (3) reports the results of the estimation. Not many variables are significant. In particular, similar to Meier and Sprenger (2010b), socio-demographics variables are not significant. The variables accounting for the type of jobs also do not appear significant. The effect of these variables (i.e. variables that are slow-changing), however, is difficult to estimate in a such short panel. Therefore, we have estimated a random effect model (not reported but available upon request), and the conclusions are similar. Moreover, the Hausman test is in favor of the fixed-effect model.

The few significant variables, however, are the one theoretically interesting. First of all, the financial situation of the family seems to matter in affecting the head of household's discount rate: the higher the level of debts, the higher the level of discount rates. Financial constraints and bank access, however, do not play an important role. ${ }^{3}$ As it has also been highlighted in the literature, the (financial) risk aversion is highly correlated with discount rate. Our results support this view: the higher the risk aversion, the higher the level of discount rate. Finally, the dummy variable which accounts for the second wave (year 2010) is positive and significant suggesting that discount rates are not stable over time.

Table (4) reports the results for the fractional probit model. For brevity, we now report the results for the variables which are of our interest or significant. We use the two methods suggested by Papke and Wooldridge (2008). The two sets of estimations tell a consistent story. The magnitude of the coefficient (BETA), however, is not directly comparable to the estimate from the linear model. To make a comparison with the linear model we need to refer to the average of partial effects (APE). Apart from few exceptions, the variables that turned out to be significant are the same as in the linear model. The magnitude of the effects is also similar. Household debts again positively and significantly affect the discount rates. Whenever the household hold debts, the average partial effect on the discount rates is about 10 percentage points, which is 5 percentage points below the linear model. As in the linear model, the other financial variables (bank access, financial literacy and constraints) are not statistically significant, whereas the number of income holders within the household significantly reduces the level of discount rates. These results thus suggest that it is the financial situation of the household (rather than the access to financial markets) affecting the discount rates. The results for the risk aversion are also in line with the linear regression, with the magnitude of the coefficient being very similar (7 percentage points vs 9 percentage points).

Differently for the linear model, the effect of interest rates at which households can borrow money (for a mortgage) is now statistically and economically significant. An increase by 1 percentage point in the interest rates corresponds to about 5 percentage points increase in discount rates. Finally, both fractional probit specifications confirm time-preference instability. The economic impact, however, is much larger than the linear model being about 20 percentage points.

\footnotetext{
${ }^{3}$ Results are identical if we use the two different measures of financial constraints, replacing FIN_CONSTRAINED1 with FIN_CONSTRAINED2.
} 
To sum up, these results are consistent with the previous literature: importantly, the effect of socio-demographic is not significant (Meier and Sprenger (2010b)). Moreover, individuals who holds debts are more likely to have unstable preferences (Meier and Sprenger (2010a)). Though significant, the effect of interest rates is not economically sizable, whereas the effect of other financial variables is not significant. The residual effect, however, which remains unexplained, highlights that a significant part of individuals do not have stable preferences. Overall, these results - in line with previous studies (Reuben et al. (2010), Meier and Sprenger (2010b)) - support the view that individuals have a tendency to modify their discount rates, which is related to an underlying individual trait. This opens the possibility to investigate other individual unobservable characteristics as possible drivers (e.g. personality traits).

\section{Robustness}

Even though socio-demographics characteristics do not appear as significant regressors (i.e. to directly affect the level of change in time-preferences), it is still interesting to see how time preferences changes across various socio-demographics groups. In Table (5) below, we report the main results for different sub-groups carried out according to the model presented in the previous section (for the sake of brevity we only report APE for QMLE). ${ }^{4}$ In line with previous works that find gender differences in time preferences (Dittrich and Leipold (2014)), we do observe some gender differences also in changes in time-preferences. In particular, females appear to be slightly more time inconsistent than men ( 0.223 vs 0.181$)$, with risk aversion also being significantly correlated with the change in time-preferences. We observe a similar pattern when we compare low educated (less than high-school diploma) with more educated individuals (more than high-school diploma). Even in this case low educated have higher levels of instability ( 0.232 vs 0.177$)$, which is also significantly correlated with risk aversion. When comparing the results across different age group (not reported), it is interesting to note that the younger ones (below 40 years old) do not exhibit any instability, but only a significant correlation with risk aversion. The opposite is true for the age-group above 40 years old. Finally, we check the robustness of our results for insecure and permanent workers. Even though the labour condition do not directly affect time-preference instability we do observe a significant high level of instability among the group of insecure workers. This latter results further validate the possibility that psychological factors (which are unobservable in the present study but significantly correlate with individual reaction to uncertainty) might be important drivers of time-preferences instability.

Given the nature of our dependent variable, we further check the model specification relying on a two-sided censoring model with fixed effects. In particular, we rely on the estimation

\footnotetext{
We refrain from adding any interaction term between these variables and the yearly dummy, as the model is non linear, and the coefficients on the interaction terms (i.e. how the effect of one variable changes when another variable changes) do not provide the change in the partial effect of the variables. Moreover, especially in panel model, the results of hypothesis tests are an artifact of the functional form and do not necessarily have an economically meaningful content (Greene (2010)).
} 
strategy based on moment conditions constructed from re-censored (or re-truncated) residuals developed by Alan et al. (2014). Results (not reported but available upon request) are consistent with the previous ones. Specifically, individuals seems to have unstable time-preferences, in a way that is significantly correlated with risk aversion. This holds true especially for individuals who hold debts.

Finally, we have checked the robustness of our results relying on principal component analysis in order to reduce the number of variables accounting for labour and financial market conditions. Even in this case, however, no significant differences have emerged.

\section{Conclusions}

In this paper we studied the main drivers of change in individual discount rates, taking advantage of the panel data from Italian Survey on Household Income and Wealth (SHIW). In comparison with previous work, we were able to simultaneously consider - in a panel setting - a large number of socio-demographic variables, along with the financial and labour status of the head of households. In particular, the variables accounting for these latter two drivers were very detailed, allowing us to distinguish between different degrees of uncertainty in the labour market. Our results are consistent with the results of the previous literature, and enable us to read them all together.

In particular, it turned out that the effects of socio-demographics, the level of uncertainty the head of household is facing in the labour and in the financial markets are not significant. However, individuals who hold debts are more likely to have unstable preferences. In addition, the effect of interest rates - though significant - is not economically sizeable.

The residual effect, however, which remains unexplained, highlights that a significant part of individuals do not have stable preferences. Overall, these results support the view that individuals have a tendency to modify their discount rates, which is related to an underlying individual trait. This opens the possibility for future research to consider psychological factors as possible drivers of such a change. 


\section{References}

Alan, S., Honoré, B. E., Hu, L., Leth-Petersen, S., 2014. Estimation of panel data regression models with two-sided censoring or truncation. Journal of Econometric Methods 3 (1), 1-20.

Anderhub, V., Güth, W., Gneezy, U., Sonsino, D., 2001. On the interaction of risk and time preferences: An experimental study. German Economic Review 2 (3), 239-253.

Dittrich, M., Leipold, K., 2014. Gender differences in time preferences. Economics Letters.

Frederick, S., 2003. Measuring intergenerational time preference: Are future lives valued less? Journal of Risk and Uncertainty 26 (1), 39-53.

Greene, W., 2010. Testing hypotheses about interaction terms in nonlinear models. Economics Letters 107 (2), 291-296.

Hardisty, D., Thompson, K., Krantz, D., Weber, E., 2013. How to measure time preferences? an experimental comparison of three methods. Judgment and Decision Making 8 (3), 236-249.

Krupka, E. L., Stephens, M., 2013. The stability of measured time preferences. Journal of Economic Behavior \& Organization 85 (C), 11-19.

Lusardi, A., Tufano, P., 2009. Debt literacy, financial experiences, and overindebtedness. Tech. rep., National Bureau of Economic Research.

Magri, S., Pico, R., 2012. Italian household debt after the 2008 crisis. Tech. rep., Bank of Italy, Economic Research and International Relations Area.

Meier, S., Sprenger, C., 2010a. Present-biased preferences and credit card borrowing. American Economic Journal: Applied Economics 2 (1), 193-210.

Meier, S., Sprenger, C., 2010b. Stability of time preferences.

Papke, L. E., Wooldridge, J. M., 2008. Panel data methods for fractional response variables with an application to test pass rates. Journal of Econometrics 145 (1), 121-133.

Prelec, D., Loewenstein, G., 1991. Decision making over time and under uncertainty: A common approach. Management science 37 (7), 770-786.

Reuben, E., Sapienza, P., Zingales, L., 2010. Time discounting for primary and monetary rewards. Economics Letters 106 (2), 125-127.

Ventura, L., 2003. Direct measures of time preference. Economic and social Review 34 (3), 293-310. 
Table 1: VARIABLES DESCRIPTION

\begin{tabular}{|c|c|}
\hline Variable & Description \\
\hline Discount rates & $\begin{array}{l}\text { This variable measures the discount rate of the household. It is expressed as a percentage. } \\
\text { Theoretically, it varies between } 0 \text { and } 1 \text {. In this survey can assume only } 5 \text { values: } 0,0.035 \text {, } \\
0.075,0.15 \text { and } 0.20 \text {. }\end{array}$ \\
\hline AGE CLASS & This is a categorical variable measuring the age of the head of the household. \\
\hline SINGLE & Dummy variable equals to 1 for all respondents reporting to be single, and 0 otherwise. \\
\hline DIVORCED & Dummy variable equals to 1 for all respondents reporting to be divorced, and 0 otherwise. \\
\hline WIDOW & Dummy variable equals to 1 for all respondents reporting to be widow, and 0 otherwise. \\
\hline FEMALE & Sex of the head of the household. \\
\hline EDUCATION & Categorical variable measuring the level of education of the head of the household. \\
\hline FAMILY SIZE & Household number of components. \\
\hline FAMILY INCOME HOLDERS & Household number of components earning an income. \\
\hline HOUSE PROPERTY & $\begin{array}{l}\text { Dummy variable equals to } 1 \text { for all respondents reporting to be owner of the house the house- } \\
\text { hold is living in, and } 0 \text { otherwise. }\end{array}$ \\
\hline DEBTS & $\begin{array}{l}\text { Dummy variable equals to } 1 \text { for all respondents reporting to have outstanding debts (i.e. } \\
\text { mortgage on the first house, debts from family or friends, and debts for acquiring goods). }\end{array}$ \\
\hline $\log$ INCOME & $\begin{array}{l}\text { Logarithm of the income of the head of household, which takes into account all sources of } \\
\text { income (e.g. benefits if unemployed) }\end{array}$ \\
\hline INSECURE JOB & $\begin{array}{l}\text { Dummy variable equals to } 1 \text { for all respondents reporting to have an insecure job (e.g. tem- } \\
\text { porary contract), and } 0 \text { otherwise. }\end{array}$ \\
\hline UNEMPLOYED & Dummy variable equals to 1 for all respondents reporting to be unemployed, and 0 otherwise. \\
\hline SELF-EMPLOYED & $\begin{array}{l}\text { Dummy variable equals to } 1 \text { for all respondents reporting to be self-employed, and } 0 \text { other- } \\
\text { wise. }\end{array}$ \\
\hline PERMANENT (base category) & $\begin{array}{l}\text { Dummy variable equals to } 1 \text { for all respondents reporting to have a permanent job, and } 0 \\
\text { otherwise. }\end{array}$ \\
\hline PART TIME & $\begin{array}{l}\text { Dummy variable equals to } 1 \text { for all respondents reporting to have a part-time job, and } 0 \\
\text { otherwise. }\end{array}$ \\
\hline BANK ACCOUNT SAVINGS & $\begin{array}{l}\text { Dummy variable equals to } 1 \text { for all respondents reporting to have either an account either at } \\
\text { a bank or at the post-office, and } 0 \text { otherwise. }\end{array}$ \\
\hline ASK CREDIT & $\begin{array}{l}\text { Dummy variable equals to } 1 \text { for all respondents reporting to have contacted a bank or a } \\
\text { financial company to obtain a loan or mortgage, and } 0 \text { otherwise. }\end{array}$ \\
\hline FIN CONSTRAINED 1 & $\begin{array}{l}\text { Dummy variable equals to } 1 \text { for all respondents reporting to have been refused or partially } \\
\text { granted a loan or a mortgage, and } 0 \text { otherwise. }\end{array}$ \\
\hline FIN CONSTRAINED 2 & $\begin{array}{l}\text { Dummy variable equals to } 1 \text { for all respondents reporting to have been refused, partially } \\
\text { granted a loan or a mortgage, or to have been discouraged to apply for it, and } 0 \text { otherwise. }\end{array}$ \\
\hline MIN MAX LITERACY & $\begin{array}{l}\text { Numerical variable measuring the total number of correct answers on financial issues in } \\
\text { relation to the maximum and minimum number of correct answers. }\end{array}$ \\
\hline FINANCIAL RISK AVERSION & Categorical variable measuring the level of financial risk aversion of the head of the household. \\
\hline
\end{tabular}


Table 2: (Pooled) Summary statistics

\begin{tabular}{lccccc}
\hline \multicolumn{1}{c}{ Variable } & Mean & Std. Dev. & Min. & Max. & N \\
\hline Discount rates & 0.078 & 0.072 & 0 & 0.2 & 2709 \\
AGE CLASS & 3.193 & 0.898 & 1 & 5 & 2709 \\
SINGLE & 0.149 & 0.356 & 0 & 1 & 2709 \\
DIVORCED & 0.114 & 0.317 & 0 & 1 & 2709 \\
WIDOW & 0.037 & 0.189 & 0 & 1 & 2709 \\
SEX & 1.318 & 0.466 & 1 & 2 & 2709 \\
EDUCATION & 4.372 & 1.532 & 1 & 8 & 2709 \\
FAMILY SIZE & 2.918 & 1.29 & 1 & 12 & 2709 \\
FAMILY INCOME HOLDERS & 1.746 & 0.741 & 1 & 5 & 2709 \\
HOUSE PROPERTY & 0.678 & 0.467 & 0 & 1 & 2709 \\
DEBTS & 0.319 & 0.466 & 0 & 1 & 2709 \\
log INCOME & 8.875 & 2.788 & 0 & 11.918 & 2709 \\
INSECURE JOB & 0.078 & 0.268 & 0 & 1 & 2709 \\
SELF EMPLOYED & 0.146 & 0.353 & 0 & 1 & 2709 \\
UNEMPLOYED & 0.123 & 0.328 & 0 & 1 & 2709 \\
PART TIME & 0.244 & 0.43 & 0 & 1 & 2709 \\
ASK CREDIT & 0.06 & 0.238 & 0 & 1 & 2709 \\
BANK ACCOUNT SAVINGS & 0.939 & 0.24 & 0 & 1 & 2709 \\
FIN CONSTRAINED 1 & 0.016 & 0.124 & 0 & 1 & 2709 \\
MIN MAX LITERACY & 0.666 & 0.295 & 0 & 1 & 2709 \\
FINANCIAL RISK AVERSION & 3.161 & 0.775 & 1 & 4 & 2709 \\
\hline
\end{tabular}


Table 3: LINEAR REGRESSION - FIXED EFFECTS

The dependent variable is the individual discount rates. A detailed description of the regressors is available in Table (1). Standard errors are in parentheses ().

\begin{tabular}{|c|c|c|c|c|}
\hline & $a$ & $b$ & $c$ & $d$ \\
\hline \multirow[t]{2}{*}{ AGE CLASS } & 0.001 & 0.001 & 0.002 & 0.002 \\
\hline & $(0.008)$ & $(0.008)$ & $(0.008)$ & $(0.008)$ \\
\hline \multirow[t]{2}{*}{ SINGLE } & -0.005 & -0.006 & -0.005 & -0.005 \\
\hline & $(0.032)$ & $(0.032)$ & $(0.030)$ & $(0.030)$ \\
\hline \multirow[t]{2}{*}{ DIVORCED } & 0.001 & 0.001 & -0.002 & -0.001 \\
\hline & $(0.025)$ & $(0.025)$ & $(0.025)$ & $(0.025)$ \\
\hline \multirow[t]{2}{*}{ WIDOW } & 0.007 & 0.006 & 0.012 & 0.013 \\
\hline & $(0.012)$ & $(0.012)$ & $(0.013)$ & $(0.013)$ \\
\hline \multirow[t]{2}{*}{ EDUCATION } & -0.005 & -0.005 & -0.006 & -0.006 \\
\hline & $(0.012)$ & $(0.012)$ & $(0.012)$ & $(0.012)$ \\
\hline \multirow[t]{2}{*}{ FAMILY SIZE } & -0.007 & -0.007 & -0.007 & -0.007 \\
\hline & $(0.006)$ & $(0.006)$ & $(0.006)$ & $(0.006)$ \\
\hline \multirow[t]{2}{*}{ FAMILY INCOME HOLDERS } & 0.006 & 0.006 & 0.005 & 0.006 \\
\hline & $(0.006)$ & $(0.006)$ & $(0.006)$ & $(0.006)$ \\
\hline \multirow[t]{2}{*}{ HOUSE PROPERTY } & 0.007 & 0.007 & 0.007 & 0.007 \\
\hline & $(0.012)$ & $(0.012)$ & $(0.012)$ & $(0.012)$ \\
\hline \multirow[t]{2}{*}{ DEBTS } & $0.015^{* *}$ & $0.015^{* *}$ & $0.015^{* *}$ & $0.015^{* *}$ \\
\hline & $(0.006)$ & $(0.006)$ & $(0.007)$ & $(0.007)$ \\
\hline \multirow[t]{2}{*}{ LOG INCOME } & 0.000 & 0.001 & 0.001 & 0.001 \\
\hline & $(0.001)$ & $(0.002)$ & $(0.002)$ & $(0.002)$ \\
\hline \multirow[t]{2}{*}{ BANK ACCOUNT SAVINGS } & 0.015 & 0.015 & 0.016 & 0.016 \\
\hline & $(0.015)$ & $(0.015)$ & $(0.014)$ & $(0.014)$ \\
\hline \multirow[t]{2}{*}{ FIN CONSTRAINED } & 0.006 & 0.005 & 0.004 & 0.004 \\
\hline & $(0.016)$ & $(0.017)$ & $(0.017)$ & $(0.017)$ \\
\hline \multirow[t]{2}{*}{ YEAR 2010} & $0.007^{* *}$ & $0.007^{* *}$ & $0.008^{* *}$ & 0.036 \\
\hline & $(0.003)$ & $(0.003)$ & $(0.003)$ & $(0.087)$ \\
\hline \multirow[t]{2}{*}{ INSECURE JOB } & & 0.001 & -0.002 & -0.002 \\
\hline & & $(0.013)$ & $(0.013)$ & $(0.013)$ \\
\hline \multirow[t]{2}{*}{ SELF EMPLOYED } & & -0.007 & -0.008 & -0.008 \\
\hline & & $(0.015)$ & $(0.015)$ & $(0.015)$ \\
\hline \multirow[t]{2}{*}{ UNEMPLOYED } & & 0.008 & 0.008 & 0.009 \\
\hline & & $(0.017)$ & $(0.017)$ & $(0.017)$ \\
\hline \multirow[t]{2}{*}{ PART TIME } & & 0.001 & 0.002 & 0.002 \\
\hline & & $(0.009)$ & $(0.009)$ & $(0.009)$ \\
\hline \multirow[t]{2}{*}{ MIN MAX LITERACY } & & & 0.002 & 0.002 \\
\hline & & & $(0.007)$ & $(0.007)$ \\
\hline \multirow{2}{*}{ FINANCIAL RISK AVERSION } & & & $0.009^{* * *}$ & $0.009 * * *$ \\
\hline & & & $(0.003)$ & $(0.003)$ \\
\hline \multirow{2}{*}{ INTEREST RATES } & & & & 0.008 \\
\hline & & & & $(0.025)$ \\
\hline \multirow[t]{2}{*}{ CONSTANT } & 0.073 & 0.068 & 0.041 & -0.006 \\
\hline & $(0.066)$ & $(0.069)$ & $(0.070)$ & $(0.164)$ \\
\hline 11 & 5177.325 & 5178.242 & 5189.64 & 5189.816 \\
\hline $\mathrm{N}$ & 2709 & 2709 & 2709 & 2709 \\
\hline
\end{tabular}


Table 4: FRACTIONAL REGRESSIONS (Papke and Wooldridge (2008))

The dependent variable is the individual discount rates. A detailed description of the regressors is available in Table (1).

\begin{tabular}{lccccc}
\hline & \multicolumn{2}{c|}{ QMLE } & \multicolumn{2}{c}{ GEE } \\
\cline { 2 - 5 } & BETA & APE & BETA & APE \\
\hline FAMILY INCOME HOLDERS & $-0.042^{* *}$ & $-0.006^{* *}$ & $-0.040^{* *}$ & $-0.006^{* *}$ \\
& $(0.014)$ & $(0.002)$ & $(0.015)$ & $(0.002)$ \\
DEBTS & $0.072^{* *}$ & $0.010^{* *}$ & $0.074^{* * *}$ & $0.011^{* *}$ \\
& $(0.023)$ & $(0.003)$ & $(0.022)$ & $(0.003)$ \\
LOG INCOME & -0.001 & -0.000 & 0.001 & 0.000 \\
BANK ACCOUNT SAVINGS & $(0.009)$ & $(0.001)$ & $(0.009)$ & $(0.001)$ \\
& 0.039 & 0.006 & 0.047 & 0.007 \\
FIN CONSTRAINED & $(0.067)$ & $(0.010)$ & $(0.064)$ & $(0.009)$ \\
& -0.085 & -0.012 & -0.070 & -0.010 \\
MIN MAX LITERACY & $(0.090)$ & $(0.013)$ & $(0.086)$ & $(0.012)$ \\
FINANCIAL RISK AVERSION & 0.043 & -0.001 & 0.038 & -0.001 \\
& $(0.039)$ & $(0.009)$ & $(0.039)$ & $(0.009)$ \\
YEAR 2010 & $0.045^{*}$ & $0.007^{*}$ & $0.048^{* *}$ & $0.007^{*}$ \\
INTEREST RATES & $(0.018)$ & $(0.003)$ & $(0.018)$ & $(0.003)$ \\
& $1.401^{* * *}$ & $0.202^{* * *}$ & $1.275^{* * *}$ & $0.184^{* * *}$ \\
& $(0.313)$ & $(0.045)$ & $(0.320)$ & $(0.046)$ \\
& $0.387^{* * *}$ & $0.056^{* * *}$ & $0.350^{* * *}$ & $0.051^{* * *}$ \\
& $(0.090)$ & $(0.013)$ & $(0.092)$ & $(0.013)$ \\
\hline
\end{tabular}

${ }^{*} \mathrm{p}<0.10,{ }^{* *} \mathrm{p}<0.05,{ }^{* * *} \mathrm{p}<0.01$ 
Table 5: FRACTIONAL REGRESSIONS - SOCIO-ECONOMICS SUB-GROUPs

The dependent variable is the individual discount rates in each sub-group. Estimations are based on the QMLE method for fractional variable suggested by (Papke and Wooldridge (2008)). A detailed description of the regressors is available in Table (1).

\begin{tabular}{lc|c|c|c|c|c}
\hline & \multicolumn{7}{c}{ APE - QMLE } \\
\cline { 2 - 7 } & FEMALE & MALE & LOW EDU & HIGH EDU & INSECURE & PERMAMENT \\
\hline FAMILY INCOME HOLDERS & -0.005 & $-0.007^{* *}$ & -0.006 & $-0.007^{*}$ & -0.012 & -0.005 \\
& $(0.005)$ & $(0.003)$ & $(0.004)$ & $(0.003)$ & $(0.010)$ & $(0.003)$ \\
DEBTS & $0.009^{*}$ & $0.011^{*}$ & 0.007 & $0.016^{* * *}$ & 0.017 & $0.010^{* *}$ \\
& $(0.004)$ & $(0.004)$ & $(0.005)$ & $(0.003)$ & $(0.012)$ & $(0.004)$ \\
LOG INCOME & 0.002 & -0.001 & 0.001 & -0.001 & 0.009 & -0.012 \\
BANK ACCOUNT SAVINGS & $(0.003)$ & $(0.002)$ & $(0.002)$ & $(0.002)$ & $(0.011)$ & $(0.008)$ \\
& 0.015 & 0.001 & 0.008 & 0.012 & -0.044 & 0.012 \\
FIN CONSTRAINED & $(0.016)$ & $(0.012)$ & $(0.013)$ & $(0.029)$ & $(0.034)$ & $(0.017)$ \\
& -0.029 & -0.005 & -0.014 & -0.006 & 0.081 & -0.036 \\
MIN MAX LITERACY & $(0.034)$ & $(0.016)$ & $(0.015)$ & $(0.030)$ & $(0.282)$ & $(0.027)$ \\
FINANCIAL RISK AVERSION & 0.004 & 0.007 & 0.007 & 0.004 & 0.038 & 0.008 \\
& $(0.016)$ & $(0.008)$ & $(0.010)$ & $(0.013)$ & $(0.041)$ & $(0.009)$ \\
YEAR 2010 & $0.013^{* *}$ & 0.004 & $0.010^{* *}$ & 0.003 & 0.011 & 0.005 \\
INTEREST RATES & $(0.005)$ & $(0.003)$ & $(0.003)$ & $(0.004)$ & $(0.016)$ & $(0.004)$ \\
& $0.223^{* *}$ & $0.181^{* * *}$ & $0.232^{* * *}$ & $0.177^{* *}$ & $0.565^{* * *}$ & $0.257^{* * *}$ \\
& $(0.081)$ & $(0.053)$ & $(0.063)$ & $(0.058)$ & $(0.171)$ & $(0.051)$ \\
& $0.060^{* *}$ & $0.051^{* * *}$ & $0.064^{* * *}$ & $0.049^{* *}$ & $0.165^{* * *}$ & $0.070^{* * *}$ \\
& $(0.023)$ & $(0.015)$ & $(0.018)$ & $(0.016)$ & $(0.050)$ & $(0.015)$ \\
\hline
\end{tabular}

${ }^{*} \mathrm{p}<0.10,{ }^{* *} \mathrm{p}<0.05,{ }^{* * *} \mathrm{p}<0.01$ 


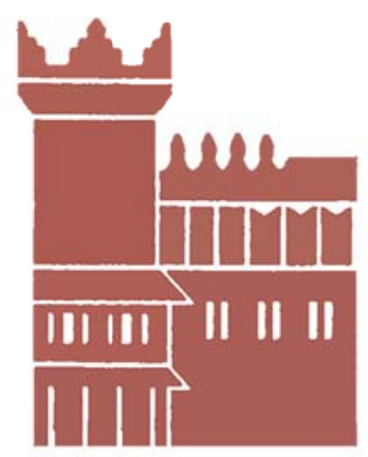

Alma Mater Studiorum - Università di Bologna DEPARTMENT OF ECONOMICS

Strada Maggiore 45

40125 Bologna - Italy

Tel. +39051 2092604

Fax +390512092664

http://www.dse.unibo.it 